\title{
Entrevista a Gastón Wagner de Sousa Campos
}

Esta entrevista con Gastón Wagner de Sousa Campos forma parte de un rastreo que venimos haciendo. Este cuarto número de la revista Barquitos Pintados Experiencia Rosario sale en el año 2020. El 2020 es el año que marca el decreto reglamentario de la Ley Nacional de Salud Mental y Adicciones como el año en que se produciría el cierre de los manicomios. Estamos en un momento particularmente complicado, no es solamente el momento de la pandemia lo que complica, sino procesos bastantes dificultosos.

El tema de este número 4 es desmanicomialización y desinstitucionalización. Pensamos la desinstitucionalización como un proceso que permite generar condiciones para que no retornen las lógicas manicomiales, para producir otro lazo en la cultura. En ese marco elegimos una conferencia que Rosana Onocko Campos y Gastón de Sousa Campos dieron en Rosario en el año 2011. Si bien han pasado algunos años, pensamos que los temas que se planteaban seguían siendo actuales, como nudos problemáticos que siguen requiriendo ser discutidos. En esa conferencia Gastón plantea la existencia de una deuda en relación a los modelos de gestión de las organizaciones estatales, cómo los modelos de gestión no evitan la alienación, la corrupción, la fragmentación en los trabajos, el desánimo generalizado. Plantea que es necesario inventar otros modelos de gestión. Por otra parte, cuando revisamos algunas experiencias en esta línea de desmanicomialización y desinstitucionalización en Rosario -en Santa Fe hay otras-, las que para nosotros son cercanas en nuestras historias de construcción, experiencias que intentaron producir prácticas instituyentes poniendo en marcha procesos de transformación, intentando esta ruptura con lo instituido, nos encontramos con una en relación al manicomio -que es la Experiencia Oliveros- y con otra en relación a la producción de salud: la institución de Atención Primaria de la Salud de la Municipalidad de Rosario.

En ambas experiencias nos encontramos con esta misma pregunta, con esta misma deuda que dice Gastón en relación a la gestión. Si se quiere producir otra cosa, habrá que cambiar los procesos, no vale sólo con el modo de enunciación política, como objetivo político, sino que se debe intervenir sobre el modo de producción en los servicios, las lógicas organizacionales. Hicimos una entrevista con Oscar Pellegrini, intentando reconstruir algo de ese proceso de Oliveros y en interlocución con compañeros-as de Atención Primaria de la Salud. Una referente de ese proceso (Raquel Musso) describía el problema que se les presentaba cuando tenían en claro que había que desarmar algo que no estaba funcionando, estaba la decisión de hacer otra cosa, pero mientras tanto necesitaban que el proceso siga funcionando, que las instituciones siguieran dando respuesta. Allí se encontraban con toda una serie de dificultades para pensar cómo producir algo diferente, instituir otras lógicas y seguir produciendo. En esta confluencia, en estas dos experiencias aparece como interlocutor Gastón.

Silvia Grande: Gastón, ambas experiencias te ubican como alguien que les permitió pensar, no saben si hicieron exactamente lo que vos decías porque después hicieron otras cosas (risas), les salieron otras cosas dicen, pero fuiste la persona que identifican en torno a esta cuestión, para pensar algo tan dificultoso como la gestión necesaria para producir algo diferente como este proceso de desinstitucionalización. Queremos que nos cuentes acerca de esa interlocución y de los encuentros y desencuentros en esa apuesta que es pensar una gestión acorde a esa utopía. 
Gastón de Sousa Campos: Gracias a usted Silvia, a Iris Valles, a la Universidad de Rosario. Siempre ha sido un placer estar con ustedes en Rosario, en vivo. Tengo mucho afecto por todo el trabajo, por ustedes como personas, como docentes, sus alumnos, todo el trabajo que hacen, la Revista; el nombre de ese afecto es saudade ${ }^{\text {. }}$

Es un tema muy amplio. Creo que tenemos un desafío macro, grande, político -todo es político- que es hacer la producción de algo, en el caso ese algo es salud, producción de vida, de gente que necesita de apoyo, de ayuda, de cuidados profesionales especializados, en una lógica que es distinta a la de mercado. Ese es el desafío mayor. Las experiencias comunistas del siglo XX no han tenido mucho éxito en la democracia institucional y tampoco en la producción de vida, de bienestar, de salud. Hay excepciones: el sistema de salud de Cuba. Pero la humanidad siguió, seguimos nosotros, con intentos en los sistemas públicos, en las políticas públicas de salud, de ciencia y tecnología, de enseñanza, de educación, intentando tener modelos de producción de conocimiento, de tecnología, de salud, en una lógica solidaria, una lógica no basada en la competencia, en el darwinismo social. Creo que ese es un desafío mayor, estamos intentando hacer eso, en sistemas, en países, en un mundo globalizado capitalista, con una hegemonía muy fuerte de una política neoliberal y ahora de un neoliberalismo conservador, como en Brasil, como en Hungría. Se llama fascismo, un fascismo para la implementación del capitalismo de concentración. Hay un desafío mayor, la humanidad; los movimientos sociales seguimos insistiendo con ese tema de desarrollar un sistema público con una lógica de defensa de la vida, de la ciudadanía, de los derechos sociales en salud. Pasaron 30 años de cuando empecé con esta cosa de pensar en la gestión, yo partí de eso, incluso usé un poema de Bob Dylan, para el epígrafe de mi libro donde hablo sobre gestión, sobre la reforma de la reforma, que decía:

"Ahora no estamos tan orgullosos.

Ahora no hablamos tan alto."

Fue en la época de la caída del muro de Berlín, de toda una crisis de las referencias culturales, de la contracultura de los años 60-70, la liberación personal, del comportamiento de la sexualidad. Foucault ha estado acá en Brasil en el año 1979, fue a Río (de Janeiro); yo no fui a escucharlo pero lo grabaron. Yo fui muy influenciado por Foucault pero peleé con él, para liberarme de algunas cosas. Para eso he usado el pensamiento histórico dialéctico, de Marx y de Gramsci, pero también el pensamiento dialéctico de Freud, de Winnicott. ¿A qué llamo dialéctica? A que los productos son siempre híbridos; que las cosas, la mercancía tiene muchos rostros, caras, tiene muchos semblantes. Marx hablaba de la mercancía con dos semblantes: el valor de cambio pero también el valor de uso; la mercancía para circular, para existir necesita atender -en alguna medida- a necesidades, que la gente considere que tiene utilidades. El valor de uso, es un concepto liberal, conservador de la economía clásica.

Foucault me impresionó por dos cosas. En la salud, por la crítica de la biomedicina, la crítica de la clínica pero con un enfoque estructuralista, posestructuralista, que apuntaba a que la biomedicina tiene un efecto, una producción de control social. En esa época estaba mucho con el valor de cambio, el sistema público de salud, esa capacidad que tenía la salud pública y la medicina, la clínica, de formatear a la gente, de formatear a la sexualidad, al comportamiento,

\footnotetext{
${ }^{1}$ Sentir nostalgia, extrañar en portugués.
} 
al estilo de vida (él no usaba ese concepto). Mi rebelión fue: es cierto eso, pero junto con eso la salud pública, la medicina, producen valores de uso. Los diabéticos necesitan insulina, la insulina es parte de la canasta básica del diabético contemporáneo; si hay derecho a la salud, es como el arroz, el feijón, la carne. Hay que pensar la producción de salud con semblantes: el control social, la dominación, la subordinación de la gente, pero también hay que pensar la producción de la vida, junto con la medicalización, junto con daños. Hay otro semblante distinto al daño, hay beneficio también. Hay el control del cuerpo, de la subjetividad, de la vida, de la existencia de la gente por los profesionales de salud y por las instituciones de salud. Cuando dijo eso fue una liberación para mí, porque yo venía de la medicina interna con tendencia para el generalismo, para la atención primaria, pero yo consideraba útil tratar a la gente contra el asma, hacer la prevención de gente que no está enferma, como las embarazadas. Yo estaba en San Pablo estudiando salud colectiva, la determinación social y todas esas cosas, yo logré hacer una síntesis y pensar el trabajo en salud como mezclas, como hibridación de esas experiencias más centradas en lo social, en lo subjetivo, el psicoanálisis, parte del cognitivismo, Piaget, la pedagogía, la prevención, Paulo Freire. Basándome en todos ellos, pero también en lo biológico, en el cuerpo, en lo biomolecular, en los fármacos, intentando usos racionales, disminuir la medicalización, tener otra lógica. Eso desde una perspectiva del trabajo en salud. Entonces en la salud colectiva, en la salud pública reformulada, yo soy un poco extraño, yo peleo al afirmar que la determinación social es reduccionista, también, como la biomedicina es reduccionista; producen verdades en parte. El área psi también, si tomamos sólo lo individual, lo personal, es un reduccionismo. Pero no es todo mentira, hay una formación de modos de vida, desde la infancia, la preinfancia, este es un punto. El segundo punto, que está más cerca de lo que me preguntabas, es sobre la gestión. Foucault hablaba en aquel entonces sobre micropolítica y después sobre el biopoder. Él no hablaba tanto de la determinación de la estructura económica, como Althusser, pero las estructuras para él eran episteme, saberes, padrones institucionales de producción de subjetividad, de modos de vida. Yo pensé: si hay micropoderes, ¿cómo sería posible hacer una gestión de los micropoderes? Foucault en los últimos años de vida dejó de hablar de la muerte del sujeto, pero hasta ocho años antes de su muerte, decía no hay sujeto, los sujetos están muertos. Hay una pregunta que Foucault no responde para mí: ¿cómo existe Michel Foucault?, alguien tan crítico, tan rebelde, con la sexualidad tan distinta de la producida por la hegemonía; esto ya es Gramsci, entonces. Yo empecé a pensar gestión con esas influencias: cómo pensar un proceso de salud complejo, más la teoría de la complejidad, es microbiológica, es clínica, personal, subjetiva, pero siempre está mezclada con lo cultural, con lo social, con lo institucional; y cómo enfrentar el micropoder, cómo ampliar el poder de los sujetos, individuales y colectivos. Eso pasa por cambios políticos generales que yo estudiaba en aquel entonces. Creía un poco más que hoy en la posibilidad de democratización radical, de democracia directa, de una cosa que llamábamos socialismo, la producción de sociedades con bienestar. Todo el tema de la gestión, yo no veo la gestión en salud aislada, el SUS ${ }^{2}$, el movimiento sanitario ha puesto mucho énfasis en eso, no hay gestión en salud, ni en educación, aislada del trabajo en salud, de la clínica, de las prácticas preventivas, de promoción en salud comunitaria. Hay que tener una coherencia, entre los modelos de gestión, entre los modelos institucionales. Para mí, la desinstitucionalización pasa por

\footnotetext{
${ }^{2}$ Sistema Único de Salud de Brasil.
} 
la construcción de nuevas instituciones, un grado de democracia, de compartir saberes, poderes, decisiones, deliberaciones, mucho mayor a lo que es la tradición incluso de la gestión comunista o socialista de los sistemas públicos. Tenemos que inventar instituciones con los actores que están involucrados, que son la gente, los usuarios, los enfermos, las comunidades, los colectivos, los profesionales, los trabajadores de salud, en general; pero también con la gente que gobierna, que representa al Estado, porque si son políticas públicas una relación tienen con el Estado, con el mercado también, que no fue eliminado, tiene una relación muy próxima con el Estado. Mi esfuerzo es ese, es una tentativa, en salud mental, en atención primaria, en los hospitales, en la universidad donde soy docente. Como decía Freire y los constructivistas, el saber no está sólo en el científico, en la universidad, está en la experiencia, en la vida, en la existencia pero está en el científico también. Con el pasar de los años, yo leí a Gramsci -que sacó de Hegel- que no hay un nuevo absoluto, esa es una concepción religiosa, idealista, lo nuevo está siempre mezclado con el pasado. Cuando los republicanos conservadores de EEUU -Reagan- empezaron a cerrar manicomios y a tirar a la gente en la calle, era deconstrucción pero sin construcción de nada. Acá en Brasil, en Italia, en el Reino Unido, estamos haciendo distinto: tratamos de deconstruir lo viejo pero poniendo junto lo nuevo, y eso mezcla entonces la clínica ampliada y compartida, la atención primaria incorpora la tradición de la biomedicina, de la bioenfermería, de la bioodontología, incorpora la tradición psicoanalítica, pero en otro escenario, con otra mezcla. Yo he tenido la gracia de no respetar fronteras entre los paradigmas, siempre me autoricé a mezclar psicoanálisis con clínica médica, con atención primaria, pedagogía con clínica médica, educación y salud. Con cada individuo es una relación clínica de cuidados, pero también pedagógica. Intento ser constructivista, él sabe, él está enfermo, ella tiene la experiencia. Es necesaria la transdisciplinariedad, que sea transparadigmática, pero hay que encontrar soluciones operativas, que tengan viabilidad pragmática, que atiendan a la necesidad, pero que consideren las posibilidades culturales, institucionales, científicas, presupuestarias. El tema de lo operativo, de lo concreto, de acercarse desde esa teoría.

El marco de la gestión tiene un desafío mucho mayor del que imaginamos. ¿Será posible producir una sociedad solidaria de bienestar?, manteniendo vivos seis mil millones de personas. Somos 230 millones de personas en Brasil con un grado de desigualdad increíble, en este contexto cómo acercar estos conceptos referenciales, conceptuales teóricos, siempre abiertos. Estamos siempre en obra, una obra en producción, una obra abierta, pero con pragmatismo, de manera operativa, no puede ser abierta solo para tener dudas, hay que intentar hacer lo mejor. En salud mental, excepto la psiquiatría tradicional que es cada vez más farmacológica, cada vez más de los síntomas, cada vez más estricta; más que la neurología, la neurología incorpora más transparadigmas, estudia lingüística, pedagogía. La psiquiatría se aísla en sus identidades idealizadas de las enfermedades con medicalización de síntomas, con una capacidad de rehabilitación muy baja. Nuestro movimiento de salud mental en el mundo, con diferencias entre ellos, pero en general tiene una efectividad de rehabilitación, de producción de vida, de reinserción (abandonando el tema de la curación), de reducción de daños, de mejorar la calidad de vida, de mejorar coeficientes de felicidad, de autonomía, de libertad, de iniciativa. ¿Cómo hacer gestión?

Yo fui descubriendo que el trabajo en salud es muy específico; me ayudo Aristóteles, el tema de la techné y la praxis. La techné es una línea automática, logra el objetivo, que es la productividad, aun cuando también enferma a los trabajadores que están en la línea de producción. 
En salud la techné no es efectiva, no es productiva. En los sistemas nacionales de salud hay evidencias sobre eso, son más eficientes y más efectivos, tienen mayor capacidad de resolver problemas de salud que un sistema de mercado como Norteamérica. Gana en todo, en años de vida, en calidad de vida, con costo menor, con atención primaria, con prevención, con cuidado, con inversión en la gente, en un montón de concepciones. La especificidad de salud, como praxis, es que los modelos de gestión tayloristas, neotayloristas, gerencialistas, no son efectivos, dificultan, reducen la calidad, en un efecto negativo.

Volviendo a lo macro, tenemos que inventar una gestión en salud, un sistema de salud que esté más cerca de la sociedad civil y del Estado. Gramsci decía el Estado no va a desaparecer, la sociedad civil va a controlar al Estado. Yo defiendo que los sistemas de salud tengan una autonomía más grande en relación al poder ejecutivo, aun cuando es el nuestro, el que elegimos nosotros. La democracia representativa cambia gobernantes en las elecciones pero el sistema de salud y educación necesitan tener continuidad. En España, en Portugal, en Inglaterra, el director del sistema de salud -o la directora, son mujeres muchas veces- tiene más poder que el ministro de salud, que no es un cargo de carrera, que es un cargo del gobierno de turno. Yo fui a verificar a Portugal, cuando cambia el gobierno salen los centro-izquierda, entran los conservadores, ellos tienen el poder de cambiar 27 personas, 27 cargos, ellos no cambian los directores de salud mental, los directores de oncología, los directores de atención primaria, no son cargos del poder electo. Los distintos logran aumentar o bajar el presupuesto pero las directrices generales son de la nación, son de la constitución. Inventaron modelos de gestión que son públicos, son modelos de gestión que son complejos, porque no pueden ser corporativos frente a los profesionales. En estos 30 años tenemos un montón de experiencias, la gente toma los conceptos y hace otra cosa, que es necesaria, que es posible, que es específica de salud mental o de atención primaria, y eso es muy bueno. Por último, necesitamos de ciudadanos profesionales de salud; necesitamos la formación de gente de la sociedad civil, gente que necesita de cuidados de profesionales; y gente de la gestión que tenga una mentalidad de estadista, que piense en política pero no piense en política centralmente para sí mismo, para el bien de su área de especialidad, que piense en la nación, en la democracia, en el bienestar, en el Estado. El éxito de esos modelos de gestión, de sistema público de salud, de reformas radicadas en atención primaria, en salud mental, depende de gente que defienda a uno mismo, a sí mismo, pero que tiene un proyecto para la sociedad, que tenga una visión de ciudadanos, que tenga una visión del colectivo también.

Iris Valles: Hay distintos niveles de preguntas. Referís que para que se produzcan esas reformas sería necesaria una hegemonía -me aparece muy fuerte- del discurso sanitarista. No sé si en Latinoamérica es así, hablo más de la experiencia argentina, los distintos movimientos en salud, están muy ligados a los actores políticos, no tanto a un discurso sanitario, por más fuerte que haya sido, esa es mi visión. La otra cuestión sería: ¿cómo vio Gastón eso en los procesos nuestros? En Oliveros, la gestión institucional, qué era lo que en ese momento se podía hacer; cómo se cambió la propia unidad manicomial, ¿se transforma en otra cosa, en ese momento? Hasta el día de hoy, por ejemplo, la presencia de abogados en los equipos tiene su marca. La pregunta que me deja picando en relación a lo que planteás en tus libros sobre la cuestión de responsabilidad y autonomía, quizás esta sea una pregunta más para el final, más actual: en el marco de la pandemia, cómo se tensionan esas dos cuestiones, responsabilidad y autonomía.

G.deS.C.: La perspectiva muy sanitarista, que hable de gestión en salud y de trabajo en salud. 
Yo soy dialectico, yo creo que hay posibilidad en salud y en educación, incluso en el marco del capitalismo hay posibilidades de avanzar más. Usted tiene razón porque la deuda de la gestión pública no es sólo en salud. Los gobiernos de izquierda, de centro-izquierda en Brasil, de Lula, de Dilma, en los que participé, no han priorizado el cambio de la gestión pública. Seguimos con la antigua, fue mi mayor crítica. Yo intenté radicalizar esto, las políticas de cambio son muy importantes no son secundarias. En Latinoamérica y en Brasil -yo creo que Argentina está cada vez más cerca de Brasil, infelizmente- la desigualdad es creciente, la degradación de la vida urbana, de los barrios, hay más villas miseria. La mitad de las ciudades brasileras son villas miseria, la seguridad pública es para matar gente, es para la elite la salud, la política del SUS. La supervivencia depende de que haya educación pública, que hagamos reforma urbana, una urbanización con participación, con cogestión de la gente, respetando la cultura, el transporte público. Todo eso la pandemia está demostrando que acá es inviable: la media de permanencia de los trabajadores brasileros en el transporte público es una hora y media al día; en una ciudad como San Pablo, casi tres horas. Todo esto muestra un grado de explotación, incluso yo creo que ese movimiento del populismo de derecha, con Bolsonaro acá, el fascismo, tiene un apoyo popular que demuestra la dificultad que los gobiernos de centro-izquierda han tenido de mejorar estos problemas crónicos, incluso la exclusión de gente. Seguimos fuerte en el nordeste, el 70\%; la izquierda sigue más fuerte allá. Populismo de derecha muy fuerte en el sudeste, Río (de Janeiro), San Pablo. La cronificación, la salud no va sola. El tema de la democracia. En un debate con la gente de Buenos Aires, Mario Rovere dijo -yo me puse a llorar- que con Bolsonaro no habrá SUS; yo tardé en responder porque me emocioné mucho. Él estaba subestimando la capacidad de resiliencia del SUS y de la educación pública. Bolsonaro eliminó el ministerio de salud, quedó fuera de juego con la pandemia: en tres, cuatro meses logró paralizar, aislar a los técnicos, la vigilancia en salud. Las provincias, los municipios, los profesionales y la sociedad estamos intentando hacer cosas. Rovere tiene razón, pero no de inmediato, pero a mediano plazo él tiene razón. Si no impedimos el fascismo, sino hacemos una defensa de la democracia, no hay futuro. El SUS no sigue sólo. Una política neoliberal muy radical ya estaba implantada antes de Bolsonaro. En los últimos cinco años el presupuesto del SUS estaba disminuido, estamos perdiendo equipos de salud de familia en Río de Janeiro. Tenemos hospitales semicerrados con ociosidad brutal, no hay reposición de trabajadores que se jubilan, que se van. El presupuesto real de la salud pública del sur está cayendo hace cinco años. Bolsonaro está agravando y radicalizando. Entonces perdón por el sanitarismo, usted tiene razón.

Con respecto a Oliveros, con todo respeto, yo hace años que no voy, entonces no puedo hablar desde la experiencia concreta. Tengo nostalgia de la gente, valoro mucho la experiencia, pero me parece que la experiencia internacional es que hay que cerrar los manicomios, los psiquiátricos, para humanizar y mejorar el modelo de atención. Hay que crear centros de atención psicosocial; núcleos de atención; centros de convivencia; salud mental en la atención primaria, salud mental en la urgencia, en emergencia, en los hospitales generales. Hay que ser más radical. No estoy criticando porque no sé si es posible ser más radical en Oliveros, en Argentina, pero como tendencia, como proyecto de futuro. Es importante tener proyecto de futuro, si no nos quedamos pesimistas. Yo creo que Oliveros no va, no va, hay que deconstruir, construyendo otras alternativas, ya que es un municipio chico. Yo sé que hay todo un problema, salió la ley nacional pero no es una política nacional presupuestaria; el sistema de salud argentino es muy 
fragmentado, el ministerio nacional y los provinciales, y las secretarias municipales, o sea, todo un lío tan grande o quizás mayor que Brasil. No estoy haciendo una crítica, pero como modelo, como proyecto es cerrar los psiquiátricos monovalentes; aunque no sean más manicomios, como se puede llamar el manicomio antiguo, no funciona de todos modos, no tiene efectividad. No incrementa el cuidado. Y, por último, está la posibilidad de autonomía. La autonomía individual termina en la colectiva, dice Voltaire y dicen los iluministas. Yo creo que eso es muy serio, o sea, no podemos tener autonomía contra la ley, contra el interés de la mayoría. El empresario no puede tener autonomía a base de explotar a los trabajadores, tiene que haber leyes de protección laboral y más. Entonces yo creo que la pandemia es un tema de responsabilidad colectiva, y la autonomía familiar, individual, empresarial, entran en un conflicto muy grande. Tiene que predominar la responsabilidad colectiva. El problema de Brasil es que quien habla en nombre de la nación, que es el presidente de la República, del ministerio de salud, está estimulando la rebelión individual y usa el término norteamericano: la desobediencia civil. Contra la cuarentena, contra el uso de mascarilla o barbijo, contra-contra-contra. Bolsonaro no habilitó el 60\% del presupuesto correspondiente al SUS. Ha propuesto que la población se arme contra los fiscales sanitarios, contra los agentes de salud, contra la gente que hace. Bolsonaro habla todo el tiempo de la libertad y sus militantes también (ellos tienen militantes): libertad individual, libertad de emprendimiento, libertad de tomar las tierras de los indígenas porque no son productivas, ese es el concepto que ellos manejan. Pero la palabra es la misma. Es una autonomía muy radical. Ahora, el tema del autocuidado, de la participación, creo que sigue en la pandemia, por medio de conferencias web, de prestación de cuenta -los servicios de salud tienen que prestar cuenta de lo que están haciendo-. Porque aumentó mucho la violencia autoritaria foucaultiana de la salud pública, de la nuestra. La gente que está ingresada en terapia intensiva hasta ahora, hasta quince días atrás, los equipos nuestros del SUS no dejaban comunicar, no daban noticias a las familias. Nunca pensé que iba a pasar algo así aquí en el sistema de salud. Entonces el autoritarismo sanitario se incrementa también. Hay ese estímulo acá a la rebelión, pero es también un no respeto al derecho del que está ingresado, de los familiares que están afuera, los amigos. Los enfermeros que se rebelaron hacen cartas para acá y para allá, ponen sus celulares para la gente que está internada. Están inventando maneras de disminuir el autoritarismo sanitario, médico, epidemiológico y todo eso que incrementa la epidemia en un grado muy grande. Entonces creo que es un desequilibrio muy difícil ese, pero ahora está muy difícil. La consigna de liberar en Brasil está con los fascistas, está con los otros. Pero ellos hablan todo el tiempo de libertad. Ahora perdón por el sanitarismo.

S.G.: Ahora, justamente, una aclaración si no estás mucho en contacto: la pregunta por la Experiencia Oliveros venía no como actor sanitarista sino como actor político para nosotros en el campo de la salud mental. Yo me quedé pensando cómo la obra trasciende al autor. Porque vos has sido una referencia muy fuerte. Yo llegué cuando ya estaba producido el hecho más gestante de esa experiencia donde estaba Gustavo Castaño, Oscar Pellegrini, Miriam Bollini y tantos más, que sería injusto cerrar la lista. Lo que a mí me llama la atención de esa experiencia, -justamente porque no estaba en su producción original cuando llegué ahí- es el efecto de esta propuesta de cómo pensar lo institucional y los equipos de trabajo. Tuvo un impacto que ellos, como actor político, generaron esa característica de nuestra salud mental, especialmente en la región. Es decir, dos paradigmas, dos sostenes, dos experiencias: Atención Primaria Municipal y Experiencia Oliveros. Porque es desde las entrañas del manicomio que surge con claridad el 
rescate de la territorialidad de la atención primaria y el cierre del manicomio. De hecho, hoy no está cerrado por falta de decisión política. Bueno y ahí, si bien las experiencias se degradan, se deterioran, se vacían mucho, por suerte porque, como vos decís, no queremos más manicomios. Sí es justo reivindicar que el valor que le otorgamos es que mucha de las discusiones y las nuevas propuestas en salud mental surgen desde la Experiencia Oliveros y vamos al encuentro con Atención Primaria.

Tu propuesta de equipo, de cómo conformar un equipo, de cómo gestionar una institución, después tenía estas consecuencias. No estaba dividido, una cosa el territorio, otra cosa el manicomio. No, eran todos los territorios lo mismo. Justamente en la lógica manicomial había que aplicar una lógica territorial que excede las paredes del manicomio. Eso es lo que distinguió al grupo. Por eso digo, ya que hablaste de obra, la obra excede al autor.

Cómo en muchas cosas te hemos mencionado y se te ha remitido a vos, especialmente quienes se atuvieron a tu experiencia, y excede lo que vos mismo imaginás respecto a sus efectos.

G.deS.C.: Sí. Ahora mire, usted estaba hablando y me acordé de la experiencia de Antonio Lancetti y David Capistrano. Ellos tenían un manicomio allá que se llamaba Anchieta, que era del SUS pero privado; el SUS compraba servicios. Y para desarmarlo, distinguieron mil propuestas de cogestión, de composición de equipos. Pero desarmaron el manicomio en seis meses. En cada ala crearon equipos de profesionales, no sólo con psiquiatras, enfermeros, psicólogos, con participación de las familias, de los usuarios, de la gente y salían por el territorio. Porque la mayoría de la gente vivía en la misma ciudad, en Santos, en la macro Santos. Entonces era posible desde la intendencia construir alternativas, modelos alternativos en atención primaria, en la salud mental, CAPS ${ }^{3}$, etc. En la medida que en el territorio, en las regiones, se iba construyendo salían enfermos y profesionales. En seis meses estaba cerrado el manicomio. Acá en Campinas hicimos lo mismo, aprendimos con ellos. Con el Cándido Ferreira que era un manicomio total, increíble, filantrópico, una ONG pero manicomial, fuimos saliendo. Tardamos un año, políticamente fue más difícil, pero fuimos saliendo. En cuanto estábamos allá llevamos adelante muchos de nuestros principios en el manicomio en movimiento, digamos así. Pero el objetivo era salir afuera, sacar, desmedicalizar, desinstitucionalizar. Pero ya se salía con un equipo de muchos profesionales, con acompañantes terapéuticos, o sea con cuadros de personal, con acuerdo de la intendencia se creaba un CAPS en el territorio, equipos de salud mental con apoyo matricial, esa lógica del territorio. Es decir, una desinstitucionalización seguida de la creación de una nueva institución.

Ahí, adelantando un poco, en nuestra nueva institución habrá problemas. Tendrá control social, producirá daños, atenderá necesidades de salud, hará rehabilitación, pero un control social distinto del manicomio. Ese es un problema acá. Porque al criticar los problemas de la salud mental en atención primaria, en los centros de salud mental es verdad que hay un aislamiento, una separación de la sociedad, hay una cronificación de otro tipo, se olvida que la gente no tiene sólo trastornos de salud mental, también tiene diabetes, hipertensión, cáncer de mama, problemas de trabajo y permanece muy aislado ahí. Hay un poeta de Curitiba que falleció, Paulo Leminski, que hablaba sobre los problemas de nuestras soluciones. Entonces yo siempre me acuerdo de eso: nuestras soluciones tienen problemas porque el veneno está adentro, no cambiamos todo. En toda institución habrá un grado de control social, un grado de daño. En toda institución, incluso en el paulofreirismo. Nuestros grupos paulofreirianos tienen algún grado

\footnotetext{
${ }^{3}$ Centro de Atención Primaria de la Salud.
} 
de control social. Entonces hay que mirar, hay que analizar, hay que dejar que la gente traiga más, que sé yo, hay que estar abiertos. Es dialéctico, no es eliminar por ningún sistema político mágico. Se sigue reproduciendo desde otros actores, otros conflictos, otras diferencias, pero en un grado mejor. Entonces: ¿alcanza sacar el manicomio? Sí, es mejor, hay que sacar el manicomio. Aunque el CAPS de atención primaria en salud mental no sea perfecto; no lo es. Hay que ver e intentar hacer las correcciones, esa es la dinámica. Y si no hacemos eso, la sociedad, los usuarios, no valoran el CAPS, no valoran la atención primaria. Si sólo hablamos del suceso, como los políticos tienden a hacer, nos olvidamos que la gente está sintiendo el problema en el cuerpo, en la vida concreta. El SUS tiene un montón de problemas, pero menores que antes del SUS. Es mejor que el actual sector privado que no tiene insulina para brindar a la gente, que hace una medicalización mucho más fuerte, que cuesta mucho más caro para hacer las mismas cosas que hace el SUS. Entonces le estamos mostrando, incluso a la clase media, que nuestro servicio de salud, de SIDA, de salud mental, de diabetes, de cáncer, de trasplante, son mejores que los de ellos. Por eso hay que tener una gestión abierta, una democratización para no olvidar los problemas neuróticamente, paranoicamente, para no meter los errores debajo de la alfombra como hacen las familias conservadoras. Entonces la izquierda, la democratización, pasa por transparencia, no ingenuidad, pasa por apuntar los problemas.

Yo tengo mucho respeto por Oliveros, yo me siento reconocido y el reconocimiento es muy importante para el ser humano. Que hayan utilizado mis cosas de otra manera, no me causa incomodidad, es lo esperado, eso pasa. Y mejoró, yo creo que mejoró. Permitieron hacer ese movimiento que Iris estaba describiendo de deconstrucción.

S.G.: Me parece que queda abierta la polémica en esto que planteás y que Iris lo ubica como un discurso más sanitarista (equipos de gestión). Un punto importante sería la constitución de actores que impugnan críticamente las prácticas y los modos de producción de micropoderes. La pregunta en relación a los procesos de gestión es si vos continuás ubicando -y me parece que sí por lo que venís diciendo- como ejes para pensar en procesos de gestión, modos de organización de los procesos de trabajo diferentes, si se quiere producir salud en relación a la vida. A lo que vos venías planteando, digamos como un valor de producción de vida, si seguís ubicando como ejes la cogestión, la autonomía y, por otro lado, la clínica. En relación a la problemática de la autonomía me interesaba también pensar la tensión entre el logro de autonomía -que muchas veces es leído en términos de libertad absolutamente individualista como bien lo señalaste- y alienación en los trabajadores. Porque pareciera que las condiciones de la pandemia nos pueden confrontar con un escenario en donde el desarrollo de autonomía en los trabajadores aparece mucho más limitado en torno a poder pensar otros modos organizacionales, otros modos de institución, etc. Como si el desarrollo de la pandemia nos ubicara en torno a condiciones mucho más alienantes y mucho más en retroceso en relación a generar procesos de autonomía. O sea, ¿Cómo evaluás esto? Porque para poder pensar la gestión me parece que un punto fundamental es este en torno a la alienación de los trabajadores. Y da la impresión -como vos decías también- que frente a la ausencia de políticas de protección, de condiciones de seguridad para los trabajadores, lo que pudiera fortalecerse es aquello ligado a la defensa corporativa y eso, por otro lado, podría tornarse más alienante.

G.deS.C.: Sobre la constitución de actores, usted tiene toda la razón, una sociedad más crítica, más reflexiva, más solidaria depende de factores sociales. Acá tenemos un movimiento para reglamentación de la milla de WhatsApp, de Facebook, porque los fascistas utilizan, hacen una militancia fascista por la internet muy fuerte; en la elección, pos elección, eran ofensivas. 
Muchos de ellos están en la cadena ahora, hay una ofensiva institucional. El control de los medios de comunicación, la democratización de los medios de comunicación. La izquierda, la centro-izquierda, ha estado en el gobierno federal durante 13 años, ocho de Lula y cinco de Dilma. La radio, la televisión acá es una concesión pública, no son privadas, es una concesión. Ni Cardoso, ni Lula, ni Dilma han propuesto cambiar la ley; ya está, crear una red de televisión, de radio, que fuera de los trabajadores, de los sindicatos. No hay, no lograron hacer un canal de televisión para todas las religiones ecuménicas, una sola, pública. Entonces los evangélicos tienen dos canales mayores de televisión, son de ellos. Bueno, entonces, yo no soy inocente en relación a eso, depende de la política. En relación a los partidos políticos, hay una desconfianza de la gente, inmensa, hay encuestas sobre eso. Con los partidos políticos, con todos. Están presos de la influencia de personalidades como Bolsonaro, Lula, gente carismática. Hay una desconfianza grande con los gremios, se burocratizaron, se aislaron de la base. Bueno, entonces hay que cambiar eso. ¿Qué me preocupa mucho? Yo creo en cambios, desde abajo, pero siempre estoy hablando desde arriba, desde partidos, desde los medios de comunicación; pero desde abajo es muy importante. Entonces yo me acuerdo de un concepto de Carlos Matus que es de gobernabilidad. ¿Dónde tenemos gobernabilidad? Hay que actuar como si estuviéramos en el macro, hay que producir democracia en donde estemos, en el centro de salud, en la escuela, en el posgrado. Yo actúo de esa manera, el movimiento sanitario en Brasil está cada vez más integrado con el movimiento de las mujeres feministas, con el movimiento antirracista, que está salvando al movimiento sanitarista porque si no estamos perdidos porque la mayoría de los médicos acompañaron a Bolsonaro, la mayoría, salvo muy pocos. Como también los empresarios adhirieron a Bolsonaro - hay encuestas- ahora ha disminuido, estamos en 50\%. Pero la mitad de los médicos, con todo el genocidio que hace el gobierno, siguen justificando al gobierno federal. Acá se creó hace 15 años un modelo inspirado en el SUS, un sistema nacional único de protección social; acá hablamos de asistencia social, ustedes hablan de trabajo social. Entonces, educación y trabajo social tienen que estar juntos, no habrá futuro sin la educación pública, sin un cambio, el tema de la violencia. Ahora lo que me incomoda es cómo los partidos están débiles, están con dificultades, no hacemos nada. Hay que hacer como las mujeres están haciendo. Acá uno de los componentes más importantes del movimiento sanitario que acercó profesionales, intelectuales de la sociedad, de la población, es el movimiento de las mujeres en el suburbio, en la periferia brasilera, luchando por hacer los servicios de salud, por tener un centro de salud, por garantizar insulina, vacunas, y se fueron politizando. Entrar en la conferencia es un pulmón de aire para el movimiento sanitario que no pude ser sólo una cosa de profesionales de izquierda. Pero hago mucho énfasis en el tema de la gobernabilidad, ¿dónde está?, y me desespero. Yo fui presidente de la Asociación Brasilera de Salud Colectiva -Abrasco- y teníamos tres consignas. Una de ellas era: la esperanza somos nosotros, que es no hay que aguardar de los otros, hay que ir a los otros. Segunda: hay que resistir y avanzar, hay que defender el SUS pero hay que mejorar el SUS. Y la tercera era: políticas sociales o barbarie, podemos hablar de socialismo o barbarie, o bienestar y justicia social o barbarie. Teníamos esos tres ejes.

Sobre el tema de la alienación en la pandemia. La pandemia cambió muchas cosas pero en gran medida los vicios organizacionales, corporativos, las hegemonías de la gestión siguen, la burocratización. Las ciudades que tienen una atención primaria más protagonista, más ac- 
tiva, los equipos, las alianzas con las mujeres, con gente de los barrios, etc. van teniendo una actuación frente a la pandemia distinta, de vigilancia territorial, comunitaria, de seguir con la atención a los padecimientos de salud mental, de crónicos, siguieron con eso que es esencial, con seguridad. Estas ciudades han tenido un movimiento de defensa de los profesionales más fuerte, para que los que trabajamos acá en el SUS sin equipamiento de protección individual, sin nada; que es una locura: ¿cómo aceptamos eso? Está la pandemia pero ¿cómo estar en una enfermería sin protección? Solo los odontólogos tenían protección individual acá por la epidemia del SIDA. En la epidemia del SIDA lograron, en el SUS, que el Estado le brindara a ellos máscaras, escudos, materiales descartables. Entonces yo creo que hay creación, por ejemplo, la discusión que he tenido con la Atención Primaria de Rosario, son muy creativos. El tema de salir de dentro del edificio del centro de salud y estar más en el territorio, en la habitación, utilizar internet, una manera interactiva, para hacer preguntas para hacer apoyo subjetivo. Acá algunos equipos pelearon y lograron tener una tablet con chip, con teléfono, que ahora fue ofrecida a toda la gente que está inscripta, matriculada, en ese equipo de salud para atender una comunicación. Eso no es general, en Brasil gran parte de la atención en salud fue aplastada, como usted dice, ni trabajo con los padecimientos antiguos crónicos, la gente vulnerable, incluso en salud mental, ni salieron de orientación en la pandemia, ni de vigilancia territorial. Han quedado paralizados y centralizados en el hospital, pero no fue general. Hace un mes o dos, hubo una experiencia de Florianópolis y de São Caetano do Sul, en San Pablo, una ciudad que se destacaba por ese protagonismo. Los otros están intentando retomar. Entonces, es una situación de aislamiento, de separación; pero al mismo tiempo, la salud colectiva nunca ha sido tan discutida, ni reunido tanta gente, tenemos dos seminarios por semana. Se llama Ágora, dos seminarios con temas y con multiplicidades de género, de región, de paradigma, de profesión. Nunca ha sido tan democrática, tan heterogénea. Nosotros, ¿nosotros quiénes?, los progresistas, los demócratas, los de izquierda y tengo miles de personas en cada sesión. Después sigue vivo porque sigue grabado. Entonces hay formas, es una situación muy difícil. Y esa exposición de los profesionales de salud a la vulnerabilidad obliga a pensar, a acercarse a la muerte, puede ser depresión pero puede ser repensar la vida, las relaciones, la felicidad, la profesión. "Ya que estoy, voy a ser una médica de hecho", "Ya que estoy, voy a ser un enfermero de hecho", entonces hay ese movimiento, un cierto espíritu de heroísmo; pero que no es de alienación es de acercarse, de calificarse: "Ya que estoy, ya que puedo enfermarme, ya que puedo morirme, que sea por una cosa que tenga valor", es un sentimiento muy común, incluso en la gente de hospitales.

S.G.: Pensaba que, probablemente, heroico es una palabra complicada, pero entiendo lo que estás transmitiendo y yo digo, bueno, justamente si hay algo que parece que estás planteando es que aun en el medio de esta situación se puede construir un sentido y un sentido que vaya más allá de cada uno de nosotros. Quizás es lo que estabas planteando con la cantidad de gente que se reúne virtualmente a discutir y a seguir pensando. Estas dos cosas que decís, está una en relación a la otra, porque el encontrarse y el retomar estos seminarios o estas cosas probablemente tengan que ver con la necesidad de construir sentidos colectivos. En todo caso, la posición más heroica e individual se puede transformar ahí si hay una construcción de un sentido colectivo. Me parece que hay algo de lo que vos marcás que realmente es un modo de construcción. 
G.deS.C.: Un sentido colectivo que está interesante acá en la experiencia, se construyó un slogan, salió despacito, se llama: Unión de las ciencias contra la pandemia. Es un esfuerzo de la interprofesionalidad, de infectólogos que se acercaron a la gente de salud colectiva, de la salud mental. Hay fenómenos, de los biólogos, de los microbiólogos que hablan de lo perdido, de la resistencia, que hablan de la vacuna. Entonces, estos encuentros nuestros son interprofesionales, muy interesantes; las mesas entre comillas, la gente que va y hace la presentación. Los fascistas empezaron a invadir nuestros espacios, empezaron a hacer invasión y a amenazar y a gritar: “VViva la cloroquina!”; “VViva Bolsonaro!”. Esas cosas locas y empezar a pegar la dirección de la gente, la gente se asusta. Entonces es un movimiento que encuentra incluso una oposición fuerte pero que sigue cada día más fuerte. La gente está más junta. El movimiento de los médicos de terapia intensiva dice: "Yo no vivo sin los fisioterapeutas, sin las enfermeras", "Que sería de nosotros sin..."; eso antes no pasaba. Entonces, hay corporativismo, hay cosas indignas, pero hay un movimiento y nunca se habló tanto del SUS y de la salud pública, no hablo de salud colectiva, no uso esa expresión pero hablo de salud pública. Con muchas concepciones contradictorias, controversias pero ingresó en la agenda de la sociedad. También, un cambio de los medios, incluso de los medios hegemónicos conservadores: hacen debates en la TV Globo con epidemiólogos, con agentes de atención primaria; gente que se enfermó y curó va a dar su testimonio. Está interesante. Me parece que ahora hay un grado de preocupación, de desánimo muy grande, porque acá tenemos un problema doble: un problema político gravísimo (del fascismo militante activo del presidente al frente) y un problema de la pandemia (de las deficiencias del SUS, de las ciudades).

S.G.: Acá, los fenómenos de resistencia aparecen donde peor estábamos en las condiciones y muy ligados a las decisiones políticas. El planteo que vos hacés viene encabezado por gente que no es la que estaba en las mejores condiciones pero sí con mucha potencia política. Son los extremos que aparecen, pero bueno, ese es otro tema, ya que es muy actual, digamos, es muy complejo. Pero es muy duro lo que decís de Brasil. 50\% no es que me sorprenda, pero es duro pensarlo. $50 \%$ ¿qué hicimos?, ¿qué nos pasó por encima? ¡Qué bárbaro!

G.deS.C.: Es muy duro, es muy duro.

S.G.: Y no disponer de los médicos, no es cualquier dato.

G.deS.C.: Mirá vos: hay 32\% de la gente de Brasil en las encuestas serias, en las encuestas que nosotros hacemos, que la Universidad hace, 32\% consideran al gobierno bueno. Ahora, ¿bueno u óptimo? 32\%, un tercio, pero hubo un cambio, un cambio de la cualidad, de las características de la clase social de sus apoyadores. Cuando él empezó el gobierno, tenía el mismo $32 \%$; nosotros (los de izquierda) tenemos 32\%; y hay un medio ahí que fue para acá y para allá. Bolsonaro perdió la mitad de sus apoyadores: médicos, empresarios, universitarios, clase media, clase media alta (él estaría con 15\%); pero ganó 15\% de apoyo entre la población más pobre de Brasil. Porque obligamos (el Congreso obligó), hicimos un frente político que creó un auxilio de emergencia de 600 reales $^{4}$ que es tres veces mayor que la "beca familia" (que era de 200 reales) y para una cobertura mucho mejor de gente: para los empleados, para autónomos, un montón de gente. Él fue contra, él quería 200 reales, pero obligamos y ganamos. Pero él lo está capitalizando entre la gente pobre y ha mantenido, o sea, la mitad de sus apoyadores está

\footnotetext{
${ }^{4}$ Moneda brasilera.
} 


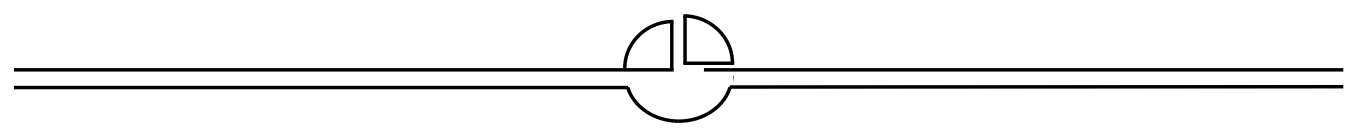

entre ex apoyadores de Lula, de la izquierda, entre la gente más pobre de Brasil. Entonces, él ha mantenido un tercio con ese cambio. Es muy triste. El mayor apoyo de Bolsonaro es entre los empresarios (que fue casi $70 \%$, cayó un poco pero sigue 53\%) y la segunda categoría profesional son los médicos (llegaron al 70\% de apoyo a Bolsonaro, ahora está en 50\%).

S.G.: Hay que crear una medicina sin médicos.

(Risas).

G.deS.C.: Casi que estamos obligados a hacer eso.

S.G.: Bueno, Gastón, no queremos robarte más tiempo. Seguramente quedan muchas cosas más, así que seguiremos en otras charlas.

G.deS.C.: Gracias Silvia, una alegría muy grande hablar con ustedes. 